sition to hemorrhoids, says: "These patients should be instructed that any irritant to the parts, such as printed paper, as a detergent, should be avoided, and above all that a cold ablution of the parts should be made after every act of defecation."

Kelsey, in such cases, advises the free use of cold water to the parts at least once a day, and further says: "This is the best tonic, astringent and anodyne of which I have any knowledge, and its habitual use would prevent a very considerable portion of all hemorrhoidal difficulties."

The same general advice is also given by Cooper and Edwards. Hence, the consensus of opinion of eminent authorities is, that the anus should receive frequent and regular ablutions, and the Bidet, Fig. 1, to which I shall presently refer, is superior to all other devices for this purpose. Yet, notwithstanding the preponderance of evidence, very few of our waterclosets are provided with any appliance for this important part of the toilet!

The Bidet, above referred to, made by J. L. Mott \& Co., is readily attached to any water-closet, and is so constructed that the anus and contiguous parts may be thoroughly drenched with hot, cold or tepid water after each evacuation of the bowels; and by attaching a vaginal pipe, since the force of the jet and temperature of the water are easily controlled, it becomes a useful apparatus for vaginal injections.

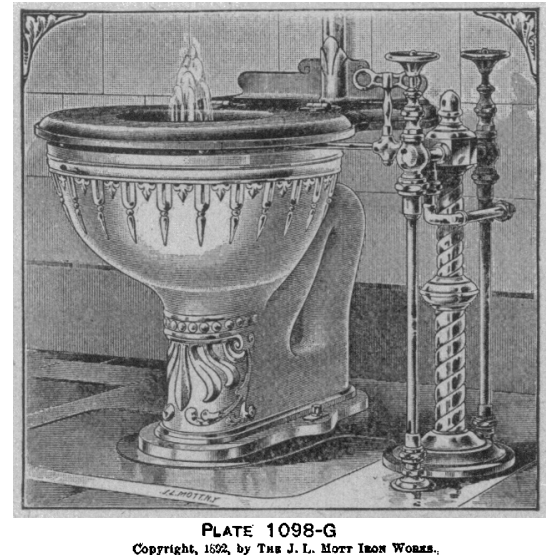

A simpler arrangement, however, and one that would answer most all purposes quite as well, is a miniature wash bowl fastened to the wall or otherwise, at the rear and on either side of the closet basin, near the seat. This basin is supplied with hot and cold water and has a waste connected with the closet bowl, that can be raised or lowered at will. From the tap, lint, fabric or tissue paper may be dampened for use, after defecation, or the waste closed and the bowl filled with water which may be medicated before using, if desired. No well appointed private watercloset is complete without some provision being made for this part of the toilet.

I find, upon inquiry, that many ingenious ways are devised for cleansing and bathing this portion of the human anatomy. Some soak a few pieces of toilet paper in the wash bowl of the bath-room; others flush the closet basin, then dampen some paper, for cleansing the part, in the water with which it refills. In both instances it is very inconvenient, and in the latter there is much danger of infection, and I should be inclined to look upon it as a rather unsavory procedure at best.
Heeding nature's call to evacuate the bowels, using paper of the quality above advised and keeping the anus and contiguous parts clean, by daily ablution, guards against chafing, filth, eczema, pruritus, fistula, piles, constipation and a host of other troubles, which are a frequent cause of many chronic constitutional diseases. It also prevents soiling of the linen, which to the sensitive and delicate-minded person is a source of great annoyance.

103 State Street.

\section{THE RIGHTS AND DUTIES OF MEDICAL WITNESSES.}

Read before the Mississippi Valley Medical Association, Nov. 21, 1894 BY HON. W. S. KERR.

MANSFIELD, OHIO.

The scope of this paper carries us to the gate of medical jurisprudence, and a little beyond, but I do not enter far its inviting domain. I deal largely with the rights of physicians and surgeons when sub. pœnaed as expert witnesses, and with the duties incumbent upon them as members of a learned and honored profession when they are called upon to testify as medical experts.

Medical witnesses have been extravagantly eulogized and unmeasurably condemned by courts and law writers. They merit both the eulogium and the condemnation. When they traffic in their evidence and appear as hired advocates the condemnation is just; when they appear as members of a great and enlightened profession, to aid in the administration of the law, and testify conscientiously, no tribute is undeserved.

The weight of medical expert evidence depends upon two qualities: 1 , the skill, learning and experience of the witness; and 2 , his honesty. The latter quality can be and should be alike in all; the former, in the nature of things, must vary and differ in degrees almost infinite in number. A physician whose practice has been confined to the small towns or the country could not be an Ericsson, nor one of three years' experience an Agnew. But all are admitted to testify to those things which they have studied and practiced, and the cause of truth and justice demands that according to their lights they should testify the truth, the whole truth and nothing but the truth. It should be recollected that not only the spirit but the form of the oath covers an opinion as well as facts testified to by expert witnesses. I do not want $t u$ lecture or read a homily on duty to the medical profession, hut the following extracts from court opinions and eminent law writers will not only justify the few observations I have made, but will also show how your high standard has been lowered here and there along the line, by testimony calling out hese criticisms. But that you may see low well the line has been held at other points, I quote alternately censure and praise, or, as earlier suggested, condemnation and eulogium.

A Scotch judge of that rugged integrity characteristic of his people, once said to a jury, referring to the medical evidence submitted on the trial: "The evidence is as unsatisfactory as any $I$ have ever seen. It leaves on the mind the distressing impression that the science of medicine is simply the science of guessing and experts. Different doctors with equal confidence and equal dogmatism, express contrary opinions upon the same condition of things. I advise 
the jury to exercise their common sense, throw overboard the medical opinion and go by the facts."

A Texas court once said: "The opinions of medical men are received with great respect and consideration, and properly so."

Judge Redfield in his treatise on the law of wills says: "Medical experts are beginning to be regarded much in the light of hired advocates, and their testimony nothing more than a studied argument in favor of the side for which they have been called. So uniformly has this proved true, in our limited experience, that it would excite scarcely less surprise to find an expert called by one side, testifying in any particular in favor of the other side, than to find counsel on either side arguing against their clients, in favor of their antagonists."

The Supreme Court of Pennsylvania says: "It is well settled that the knowledge and experience of medical experts is of great value."

An Ohio court said in reference to evidence in a murder case: "It would be but a farce to try such a question upon the strength of medical opinions, and to regard the weight of evidence always on the side which produced the greatest number."

The Supreme Court of North Carolina says: "The opinion of a well-instructed and experienced medical man upon a matter within the scope of his profession, and based on personal observations and knowledge, is and ought to be carefully considered and weighed by the jury in rendering their verdict."

The Illinois Supreme Court says: "These doctors were summoned by the contestants as 'experts' for the purpose of invalidating a will deliberately made by a man quite as competent as either of them to do such an act. The testimony is worth but little, and should be received by courts and juries with great caution. . . . It must be apparent to every one, but few wills could stand the test of the fanciful theories of dogmatic witnesses. . . . In such cases the opinions of neighbors, of men of good common sense, would be worth more than all the experts in the country."

The Ohio Supreme Court says: "Medical testimony is of too much importance to be disregarded."

Mr. Justice Grier, of the United States Supreme Court, said in delivering an opinion: "Experience has shown that opposite opinions of persons professing to be experts may be obtained to any amount."

The Georgia Supreme Court in speaking of medical evidence says: "It is entitled to great weight and consideration."

Judge Campbell, of the Michigan Supreme Court said: "The experience of courts with the testimony of experts has not been such as to impress them with the conviction that the scope of such proofs should be extended."

Thus has the shuttle of criticism, favorable an adverse, gone to and fro, weaving in the warp and woof of jurisprudence, the history of the medical witness. In the court-room he has won laurels for his profession-in the court-room he has brought reproach upon its fair name and fame. But it should be remembered that the medical expert is not the only expert whose testimony has been the subject of unfavorable judicial comment. Other experts appear quite as frequently as do physicians and surgeons, and when their evidence has been afflicted with the same vice it has been similarly characterized.

To avoid this just censure, opinions should be re- garded as facts stated under the solemnity of an oath, and not as arguments to be urged in behalf of the side calling the witness. Opinions can not be measured in reference to their soundness, as facts can be squared to accord with the truth; there must be more latitude to give room for the difference in mental processes and impressions, but they have boundaries, or else there is no exactness in medical science. Exactly opposite opinions upor the same hypothesis proves one of two things-either that the witness lacks veracity or knowledge, or that the science is too elastic to be the measure of important rights.

Courts have been called upon to unfavorably criticise medical witnesses in respects other than in reference to opinion evidence. An investigation involving the condition and position of organs which can be examined physically and ocularly, ought not to differ materially in the result. The evidence of such examination and result presents facts and not opinions. A case illustrating this point, and in which I was engaged as counsel, came under my own observation. A woman sued a municipality for damages. She claimed to have prolapsus of the uterus from a fall upon a sidewalk. During the trial eight physicians examined her-four at one time and four at another, but all within an hour or two. Four testified that her condition, in respect to the matter complained of, was entirely normal.

The other four, and their examination had been contemporaneous, testified as follows: One said he found the position of the organ abnormal in that it leaned too far back; the second that it leaned too far to the right; the third that it leaned too far to the left, and the fourth, a Nestor in the profession, said he found it too straight up.

Another case tried recently in an Ohio court illustrates how physicians may fall short in making the test which more than any other would measure the capacity, which is always the desideratum in such investigations. An application was made for the appointment of a guardian for a man who, in the meridian of his powers, was one of the most celebrated physicians and surgeons in Ohio, upon the ground that he had become an imbecile, and was incapable of managing his business. Three of the most celebrated and able mental alienists in the State testified to his soundness of mind and his capacity to do business. Their investigations, although made with ample opportunity, were limited to conversations upon subjects relating to events long past or about items of property which he had possessed for years.

An order of the court was made to examine the alleged imbecile and such examination was made. Two very simple tests did more to solve the question of incapacity than all the expert evidence. He was told to add a column of five figures. The first three were added correctly but he could add no farther. $\mathrm{He}$ was next given $\$ 1.77$ in change, consisting of seven or eight pieces and although he was able to designate the pieces, after considerable effort, he was unable to tell the aggregate. A man capacitated to do business should be able to add five figures and count a few pieces of money.

The cases in which the physician is called upon to aid the law are legion. If I were to undertake to enumerate them, the schedule itself would extend beyond the reasonable limits of a paper. Judicial 
history shows that the physician as an expert witness, shines brightest or suffers the most serious discomfiture in cases of insanity and poisoning. Both of these afford a broad field for the exhibition of brilliant professional learning and acumen, and in legal investigations usually attracting large public interest and attention. They are fields worthy of any man's conquest even though he has to burnish his weapons by the light of a midnight lamp.

It should be recollected, also, that it is only in doubtful cases where the medical witness becomes an auxiliary to the law. He should not only be able to describe and classify the subject about which he testifies, according to the science of his profession, but he must bring his knowledge down to the comprehension of the twelve ordinary men who sit in the jury box. Because, however learned he is, if those whom he is to enlighten fail to comprehend him he has failed of the object and purpose of his being a witness. In measuring the duty of the medical witness it should be borne in mind that the majority of medico-legal questions are beyond the field, and lie far outside the every-day path, of most physicians. Nineteen-twentieths of their practice, medical and surgical, never relates to a matter which is the subject of litigation. It requires study, much study, to be a giant in any profession. Those who wait until the case presents itself, before fitting to try it or treat it, gather only withered leaves and faded flowers for their victor wreaths. That the daily practice of $\boldsymbol{B}$ doctor does not bring him into contact with the insane, is no reason why he should not possess, at least, the book learning of the subject. He may not be called once a year to treat a case of poisoning, yet he should know the various poisons, their peculiar effects and symptoms and be able to make the distinctions which science enables those to make who have tarried long enough at her fountains. It is to the advantage of a physician, if he never earned a dollar in this field, to be accomplished in legal medicine. It is a part of his profession and one who succeeds in a profession is one who explores with the lamp of industry its every branch and recess, and who comes to the discharge of its every duty with a mind capable of not alone comprehending, but of applying correctly its principles.

Necessity brought into requisition the medical expert. Frequently the courts would encounter questions of fact which all the knowledge of lawvers and judges and the common sense of juries could not solve satisfactorily. If those questions related to the human mind or body, who better could assist in making light that which was dark and mysterious, than the learned physician? So he was added as a spoke in the wheel of justice, or a wheel in the machinery of the law.

Mental alienation is a broad and inviting study. Men have spent their lives and become famous in the field and yet have not conquered half its difficulties nor solved half its mysteries. But this should not discourage the physician from devoting a little time, stolen from the daily grind, to its study. Like the bread cast upon the waters it will come back to bless hin. Any doctor may be subpœnaed at any time to testify as a medical expert. Doctors as well as lawyers, and perhaps members of other professions, are judged by a standard fixed by a misconception and this misconception is deeply rooted in the common mind. In general under- standing, both law and medicine are supposed to be made up of certain fixed and unvarying rules, which when applied will solve every question and dispute and determine every diagnosis and the treatment. It is further believed that every doctor and lawyer should be able at any moment to pick up one of these rules, as a carpenter would his measure, and settle the question or tell the disease at sight. We know that these are mistaken ideas. I am not competent to speak as to medicine, but as to law, it is not so much to know the law as to know where to find it. But in general estimation a doctor, when put on the stand, is expected to shed broad light upon any subject connected with medicine and if he is not able to do so or at least appears not to be able, not only his professional dignity but his professional standing and usefulness suffer.

Physicians are brought into court to testify as to the identity and ages of persons. The Tichborne case, as to the identity of the claimant, is one of the most interesting judicial records of the world. They are asked to give opinions as to probable survivorship where persons have died at near the same time and the course of inheritance depends upon the order of death. They are required to testify as to the age of puberty and to determine the most delicate and important questions in cases involving capacity to commit rape and paternity proceedings. In cases of criminal abortion, multitation, homicide, infanticide, defloration, wounds, impotency, sterility, pregnancy and in scores of other cases and upon scores of other questions, the physician is a valuable, an indispensable auxiliary in legal proceedings, civil and criminal.

A learned legal authority says: "The jury are to be enlightened in every possible way, and as they are not selected with a view to their qualifications to try the particular issues before them, but as men possessing the ordinary qualifications of mankind, when questions arise to be determined by them, involving an acquaintance with facts not coming within the ordinary range of human experience, skilled witnesses are permitted to enlighten them. The true rule is that when the subject to be investigated so far partakes of the nature of a science or trade as to require a previous course of study or habit in order to attain a knowledge of it, opinions of experts are admissible."

In legal controversies, turning upon, or involving the condition of mind as to soundness or unsoundness, the most important as well as the most difficult questions are largely determined by medical evidence. The physician is able, as no one else can, to physically and mentally measure the man. A man may not be able to manage his business affairs and etill be responsible for crime. In criminal proceedings the supreme test is the ability to distinguish between right and wrong. This would seem a very simple and easy rule, but in its application to actual cases it calls into requisition all the acuteness and learning of both professions and in spite of all their acuteness and learning many an insane person has been executed for crime and many an offender has escaped just punishment upon the mistaken finding that he was insane. And it is no reflection upon law or medicine that this should be so. The most difficult problem with which courts and lawyers and doctors have to contend is that of real or alleged mental aberration in criminal cases and especially in capital cases. Many cases present the defense of 
insane impulse. The person charged being concededly sane, immediately before and immediately after the commission of the act. Such was the shooting of Key by Sickles. Sickles was a Congressman and eminent in public life. Key had done him a great wrong. Upon sight of Key and under the impulse of his wrought up feelings the latter was shot dead in one of the public parks of the National Capital. The defense was that his condition of mind at the moment rendered him incapable of controlling the natural impulse to destroy the destroyer of his home. $\mathrm{He}$ was acquitted.

The Mary Harris case tried in Washington during the war was a celebrated case and presented clearly the difficulty, which medical experts encounter and, as well, the duty which they must discharge when a life, especially that of a woman, is at stake. The defendant shot a man to death in the Treasury Department and her defense was insane impulse. She was defended by most able counsel, among them being Senator Voorhees, then a Member of Congress. Eminent medical experts testified on both sides. While she was imprisoned, Mrs. Lincoln sent her a bouquet of rare flowers and within a year or two last past she was married to her senior counsel. She was acquitted upon the ground that at the moment of the shooting she was incapable of controlling the impulse under which she destroyed a buman life.

A further illustration of this kind of evidence is in cases where, although the person charged with an offense is insane, it is claimed that either he still retained enough mental power to distinguish between right and wrong, or that the act was committed during a lucid interval. The question of responsibility may turn upon a brief interval of time.

Again, in civil cases, some of the most important, delicate and interesting questions, as to mental capacity, have arisen in contests of wills. The mental capacity is frequently complicated with undue or illegal influence and thus compounded make contests in which fame may be achieved by medical experts.

And still again, difficult questions as to mental capacity arise in proceedings to appoint guardians for persons alleged to be imbecile or insane. I believe medical authorities define an imbecile to be one idiotic but not born such. An old legal authority provided this test: "A person who has understanding enough to measure a yard of cloth, number twenty correctly or tell the days of the week is not an idiot in the eyes of the law." But in these days of asylums for the feeble-minded, institutions in which idiots are taught to do these things and many more, this test of responsibility or capacity would hardly be received as conclusive. And in all such cases judges, calling to their aid medical gentlemen as expert witnesses, must unravel the tangles.

Cases in criminal poisoning usually have about them the interest of mystery. In a great majority of these cases the evidence to convict or exculpate must come from the medical profession. The most important witness is usually the attending physician, and very much depends on how carefully he has noted and how clearly he can describe the symptoms. The chemist can analyze in search of the poison, but only the doctor can preservo the symptoms and appearance.

Doctors are frequently called into court, not simply as witnesses to give an opinion but to testify to technical facts, the knowledge of which was acquired by them in the confidential capacity of attending as a family physician and in aid of or against persons thus employing them. Under the common law the communications made by patients to their physicians were not privileged. Most of the States by statute have provided that such communications shall not be given in evidence if the patient objects. The privilege is that of the patient and not of the doctor. But in order to exclude them they must be made about something necessary to be disclosed in order to prescribe the remedy or treatment.

I have reserved for the last, a brief reference to the law regarding the right of medical experts to receive or demand extra compensation before testifying. If they are subpœnaed to testify to facts which came under their personal observation, their rights are not different from those of any other witness. They are bound to obey the summons of the court and if they neglect to do so, they would be subject to punishment as for contempt of court. I think, as a general proposition and in the first instance, physicians are obliged to appear in court when subpœnaed and paid or offered the ordinary fee, and that their right to raise the question does not present itself until they are propounded questions calling for opinion or scientific evidence and then the question arises hereinafter discussed. This may seem to fall short of what an expert ought to be able to demand before going to court, but the reason of the proposition lies in the difficulty of determining beforehand the kind of evidence to be elicited. 'If it was conceded at the outset that opinion or expert evidence alone was to be sought, then I think the right to demand extra compensation would exist before answering the subpœna or at least before going upon the stand.

Some of the States by statutory provision, have settled this question. North Carolina as follows: "Experts when compelled to attend and testify shall be allowed such compensation and mileage as the court may, in its discretion, order."

Iowa as follows: "Witness called to testify only to an opinion founded on special study or experience in any branch of science or make scientific or professional examination, and state the result thereof, shall receive additional compensation, to be fixed by the court, with reference to the value of time employed and the degree of learning or skill required."

Rhode Island as follows: "In addition to the fees above provided, witnesses summoned and testifying as experts in behalf of the State before any justice of the Supreme Court, trial justice or coroner, may be allowed and paid such sum as such justice of the Supreme Court, trial justice, or coroner may deem just and reasonable; provided, that the allowance so made by any trial justice or coroner, shall be subject to the approval of a justice of the Supreme Court."

Indiana has settled the matter the other way and as follows: "A witness who is an expert in any art, science, trade, profession or mystery may be compelled to appear and testify to an opinion as such expert, in relation to any matter, whenever such opinion is material evidence relevant to any issue on trial before court or jury, without payment or tender of compensation other than the per diem and mileage allowed by law to witnesses, under the same rules and regulations by which he can be made to appear 
and testify to his knowledge of facts relevant to the same issue."

In States where no express provision has been enacted the question is still an open one, unless some court of authority has fixed a rule. Some of them have, as hereinafter stated. No expert is required, whatever the rule is, to make examinations and prepare to testify in behalf to a party to a suit without such compensation as may be agreed upon. $\mathrm{He}$ might be required to do so if appointed by a court as a commission or committee in cases where the court had authority to make such appointment. He can not be compelled to attend the progress of a trial in order to enable him or qualify him to give opinions as to questions involved.

The reasons are all in favor of extra compensation. Authoritative writers on medical jurisprudence have set them forth as follows: I quote from Ordronaux: "It is evident that the skill and professional experience of a man are so far his individual capital and property that he can not be compelled to bestow it gratuitously upon any party. Neither the public, any more than a private person, have a right to extort services from him, in the line of his profession, without adequate compensation. On the witness stand, precisely as in his office, his opinion can be given or withheld at pleasure; for a skilled witness can not be compelled to give an opinion, nor committea for contempt, if he refuse to do so."

I quote next from Beck's "Medical Jurisprudence :" "If the duties on which I have enlarged are important to the community, in promoting the proper administration of justice, ought not the individuals engaged in them to receive adequate compensation? I advert to this not only because it is just in principle, but because it would remove all imputation of volunteering in criminal cases; no one can refuse being a witness when legally summoned; every one, I presume, may decline to dissection of a dead body, or the chemic examination of a suspected fluid and yet there is not, I believe, an individual attending on any of our courts, who is not paid for his time and services, with the exception of such as are engaged in these investigations.'

These authors are physicians and it may be reasonable to subtract a little from their enthusiasm, but notwithstanding, they state cogently reasons which ought to determine the rule. A good deal of learning has been expended in discussing whether the rule should rest upon the theory than the time of an expert was more valuable than that of an ordinary witness, or that upon the theory that his opinions, skill and experience are his property of which he can not be deprived without adequate compensation. The latter theory has prevailed universally where extra compensation has been authorized and it is the only tenable basis.

In a Massachusetts Federal Court in a criminal case, the district attorney moved to attach a witness as for contempt, who had failed to appear when subpœnaed as an interpreter. It is not an exact parallel but the reason is the same. The court declined to issue the writ and in the refusal is reported as saying: "A similar question has heretofore arisen and I have declined to issue process to assist in such cases. When a person has knowledge of any fact pertinent to the issue to be tried, he may be compelled to attend as a witness. . . . But to compel a person to attend because he is accomplished in a particular science, art, or profession would subject the same individual to be called upon in every cause in which any question in his department of knowledge is to be solved. Thus the most eminent physician might be compelled, merely for the ordinary witness fee, to attend from the remotest part of the district, and give his opinion in every trial in which a medical question should arise. This is so unreasonable that nothing but necessity would justify it."

One of the Federal Circuit Courts of this State (Arkausas) has decided the question in favor of the right to demand extra compensation before testifying to matters of expert knowledge. The court said : "The skill and professional experience of a man are so far his individual capital and property that he can not be compelled to bestow them gratuitously upon any party."

The Court of Appeals of Texas held the opposite rule upon the peculiar facts of the case. A physician was placed upon the witness stand and testified without objection to the facts which had come under his personal observation; when it came to his opinion as to the cause of the man's death he declined to answer without other compensation than the ordinary witness fee. The trial court sustained the physician, but the Court of Appeals held that inasmuch as he had already made the post-mortem examination he should give his opinion.

The Supreme Court of Indiana, before the passage of the statute denying the right to extra compensation, decided the question the other way, and in the opinion used the following language: "When a phy. sician testifies as an expert giving his opinion he is performing a strictly professional service. So does the lawyer, when he performs any services in a case. The position of a medical witness testifying as an expert, is much more like that of a lawyer than that of an ordinary witness testifying to facts. The purpose of his service is not to prove facts in the case, but to aid the court of jury in arriving at a proper conclusion from facts otherwise proved."

The English rule is well settled in favor of extra compensation. Justice Maule in one case saying: "There is a distinction between the case of a man who sees a fact, and is called to prove it in court of law, and a man who is selected by a party to give his opinion on a matter on which he is peculiarly conversant from the nature of his employment in life. The former is bound as a matter of public duty to speak to a fact which appears to have fallen within his own knowledge. The latter is under no such obligation; there is no such necessity for his evidence and the party who selects him must pay him.

Alabama has denied the right; other States may have done so, but the cases have not come under my observation. Upon the reason of the thing one wonders why courts have divided upon the question. An expert is one who by study and practice, skill and experience has acquired peculiar knowledge of a certain subject or matter. He arrives at his knowledge by a process akin to that through which property is accumulated, and it is as valuable as property. The latter receives the protection of constitutional provision, and is guarded as sacredly as life and liberty. Yet knowledge, by these adverse decisions, is treated as commons upon which judicial stock may graze at pleasure.

The evidence of an expert should be compensated for commensurate with its value. In criminal cases 
the amount should be fixed by the court, in civil by agreement between the expert and the party calling him. The medical expert should never have his opinions for sale. Fidelity to his profession and its great principles should be his pole star. Medicine is the greatest of the worldly professions. It deals with life and health, the dearest possessions of this sphere. For years, if not in substantial honors yet in general estimation, it has been honored above all. Its members have ornamented the most exalted stations, and in its daily work, without herald or drum beat it modestly performs its great task in life. I am th highly honored by being admitted, for this brief time, within the precincts of your order.

\section{ORIGINAL INVESTIGATIONS ON THE NATURAL HISTORY, (SYMPTOMS AND PATHOLOGY) OF YELLOW FEVER. 1854-1894. \\ BY JOSEPH JONES, M.D., LL.D. NEW ORLEANS, LA. (Continued from page 10.) Chapter III.}

Algid Form:- "As a general rule, the vascular action was much below par in the algid form. I have observed cases in which the radial pulse was imperceptible for days; more commonly, however, the pulse at the worst, though excessively feeble, was not altogether obstructed, and by a delicate and prac. ticed finger it could be felt and counted. Its rate was variable, more commonly below than above 100 per minute. I have noted it at 80 , very fine, thready, weak and readily extinguishable, and at almost all intermediate rates to 120 , with much the same char. acter. The cardiac action was very feeble. I have not observed any diminution in the relative proportions of the first and second sounds of the heart; they were often diminished in tone and force, but preserved their relative characters of duration and intensity. I have not observed any want of accordance between the cardiac action and that of the arteries in the algid form, such as I shall have to speak of subsequently when treating of some of the other forms. In general, in this form the radial pulse could be taken as a measure of the cardiac action. When the pulse was feeble, the heart was likewise proportionately so. There was no exception to this rule, as my experience of the cases goes (p. 260).

"Sthenic Form:-This class of cases generally exhibits from the outset a remarkable elevation of temperature. It is common to find an increase of 3 degrees, 4 degrees or even 5 degrees Fah., and in some instances an increase of nearly 7 degrees has been observed. We have noted the thermometer in the axilla at 102 degrees, 103 degrees, 104 degrees, and in some instances it nearly touched 105 degrees Fah. This limit I have not actually seen reached in any case, though the mercury in some instances rose considerably above 104 degrees. (The instrument employed, an English one of the kind commonly used for hospital purposes, did not admit of more minute or accurate reading than by whole degrees (p. 266.)

"Rate of the Pulse in the Sthenic Cases:-The pulse, though often full and expanded, and occasionally hard and thrilling in this form, commonly ranges but little above 100 or 110 beats per minute. I have noted it in some cases at 112,114 , and in very rare instances so high as 120 . In general, when the pulse runs above 115, the case passes into a low and typhoid state; on the other hand, I have seen wellmarked pyrexia with a pulse at 60 . It has fallen to $100,90,80$, and even 70, and in two instances to 60 , without very well marked diminution of the other pyrexial symptoms; in these latter instances it has always retained its force and expansion. Thus we not unfrequently have the combination of a pulse at 70,80 or 90 , or in general terms, under 100 , while the thermometer in the axilla shows a persistent temperature above 100 degrees Fah.

"The following combinations of pulse rate and temperature were observed in the course of my in. vestigations into the Lisbon epidemic; they are selected to show the absence of harmony and the frequent contrasts presented by the two sets of phenomena:

TABLE OF PUlse Rate AND TEMPERATURE. (Thermometer in axilla.)

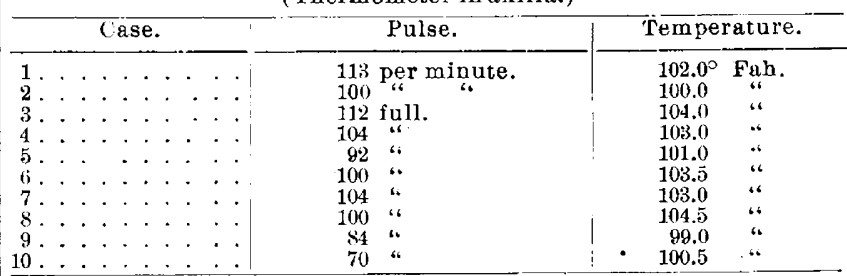

"From this table it will be seen that the highest pulse rate and the highest temperature did not correspond. On the contrary, the highest pulse at 113 had only a moderate degree of elevation of the thermometer, 102 degrees, while the pulse at 100 gave the highest temperature, and the lowest pulse rate, that at 70 beats per minute, was attended by coloration and an elevation of the thermometer to 100.5 degrees. There was, therefore, no constant uniformity of relation between the two sets of phenomena (pp. 270, 271).

Hemorrhagic Form:-I can testify to the statement, that in this form the yellow coloration constantly appears during the primary pyrexial state and while it is at its height, with the pulse over 100 , and the thermometer in the axilla registering $101 \mathrm{de}-$ grees, 102 degrees, or even 104 degrees, the thermometer indicates generally a less considerable elevation of temperature in the hemorrhagic than in the sthenic cases. I have observed the pulse at 92 degrees and the thermometer at 101 degrees Fah. in a most characteristic well-marked hemorrhagic case. The pulse subsequently rose to 100 , and 104 degrees in the same case, with elevations of the thermometer to 103.5 degrees and 103 degrees respectively, coloration of the skin being present to a marked extent. I do not, however, think that the temperature is generally so high in this class of cases. I believe that as a general rule the temperature in the hemorrhagic cases is from '2 degrees Fah. under that in the sthenic form. The transition from the sthenic to the hemorrhagic form is sometimes marked by a diminution in the rate and volume of the pulse, and a lowering of the thermometer; the patient's strength sinks rapidly at the same time, and in some cases a clammy sweat bedews the face for one or two days. This state of thinge is followed by, as it were, an explosive and universal lesion in the vascular system, leading to profuse hemorrhages at all available points of the cutaneous and mucous surfaces (pp. 274, 275). 